\title{
Effect of aluminium oxide nanoadditive on diesel along with gasoline fumigation in single cylinder diesel engine
}

\author{
A. Tamilvanan*, M. Bharathiraja**, K. Balamurugan*** and C. Sasikumar**** \\ * Department of Mechanical Engineering, Kongu Engineering College, Erode, Tamil Nadu, 638060, India. \\ ** Department of Automobile Engineering, Bannari Amman Institute of Technology, Sathyamangalam, Tamil Nadu, 638401, India. \\ *** Department of Mechanical Engineering, Institute of Road and Transport Technology, Erode, Tamil Nadu, 638316, India. \\ **** Department of Mechanical Engineering, Bannari Amman Institute of Technology, Sathyamangalam, Tamil Nadu, 638401, India. \\ * Corresponding Author: bharathiraja@bitsathy.ac.in
}

Submitted :08/05/2020

Revised :08/08/2021

Accepted : 19/08/2021

\begin{abstract}
The present investigation mainly focuses on overcoming the limitations of gasoline fumigation (GF) in diesel engines by adding up nano fuel additives. Experiments are conducted to ascertain the engine working characteristics in a single-cylinder, four-stroke diesel engine using aluminum oxide $\left(\mathrm{Al}_{2} \mathrm{O}_{3}\right)$ nanoadditives blended diesel as the main injection fuel along with GF as an inducted fuel. GF was achieved by controlling the electronic injector fitted at the intake manifold using open ECU software. Fuel map for GF was determined based on experiments with three divergent fumigation rates of $10 \%, 20 \%$, and $30 \%$ based on energy consumption and optimized using the design of experiments. The optimization results showed $10 \%$ fumigation, resulting in better performance and emission characteristics, and it is selected for this present investigation. Fumigation results showed a decrease in brake thermal efficiency (BTE) at low and medium loads and an increase at high loads. The two different mass fractions of $25 \mathrm{ppm}$ and $50 \mathrm{ppm} \mathrm{Al}_{2} \mathrm{O}_{3}$ nano liquid are blended with diesel. Compared to GF with diesel, GF along with 25 and 50ppm $\mathrm{Al}_{2} \mathrm{O}_{3}$ nanoadditives blended diesel showed an increased BTE, maximum in-cylinder pressure, and cumulative heat release rate and reduced smoke opacity, $\mathrm{CO}$, and unburned $\mathrm{HC}$ emissions at overall operating conditions. As the dosage level of $\mathrm{Al}_{2} \mathrm{O}_{3}$ increases from 25 to $50 \mathrm{ppm}$, it results in further enhancement of all working parameters except $\mathrm{NO}_{x}$ emission. Finally, the addition of an $\mathrm{Al}_{2} \mathrm{O}_{3}$ Nano additive is a suitable solution to overcome the limitations of GF in the CI engine.
\end{abstract}

Keywords: Gasoline fumigation; Electronic injection; Nano additive; Emissions; Open ECU.

\section{INTRODUCTION}

Diesel engines or compression ignition (CI) engines are extensively used for industrial sectors, transportation, and agricultural applications as a result of its maximum fuel conversion efficiency and negligible engine exhausts except for nitrogen oxides (NOx) emission (Wang et al., 2021). The most harmful emissions from diesel engines are particulate matter (PM) and NOx, which has adverse effects on surroundings (Sekar et al., 2021). Fumigation is 
one of the dual-fuel operations, which has a potential solution to reduce emissions and enhance the performance of CI engines. Here, a primary fuel called main injected fuel is injected into the combustion chamber at end of the compression stroke, and secondary fuel is called inducted fuel, which is highly volatile liquid fuel injected into the intake manifold along with air stream during a suction stroke (Ayyasamy et al., 2018). Fumigation in CI engines could result in a reduction of NOx and smoke considerably when compared to neat diesel operation. On the other hand, it increases hydrocarbon (HC) emission and carbon monoxide (CO) emission (Bharathiraja et al., 2019).

The effects of GF using a simple carburetor on fuel economy, performance, combustion, and emission characteristics are studied in indirect injection automotive diesel engine (Şahin and Durgun, 2013). The results prove that NOx emission decreases roughly about $9.65-4.20 \%$ for $50-100 \%$ Fuel Delivery Ratio (FDR), respectively. The effect of GF on a DI diesel engine fueled with waste cooking oil biodiesel (B20) blends and neat diesel is investigated (Hoseinpour et al., 2017). For the entire working points, the energy and exergy transfer throughout the exhaust gases reduce by an average of $2.6 \%$ and $6.4 \%$ for GF with diesel and B20 fuels, respectively. Fumigation of gasoline up to $5 \%$ along with diesel and biodiesel can result in considerable raise in exhaust $\mathrm{CO}$ and unburned $\mathrm{HC}$ emissions, as well as a reduction in smoke opacity, $\mathrm{CO} 2$, and NOx emissions. The use of GF in a single-cylinder DI diesel engine results in a 4-9\% enhancement of valuable power output, $1.5-4 \%$ increases of useful efficiency, and $1.5-4 \%$ reduction of specific fuel consumption. Also, the heat carried by the exhaust gas is reduced up to $4-5 \%$ for different fumigation ratios. The GF in turbo-charged an indirect injection diesel engine is investigated by Sahin et al. (2012). NOx concentration is reduced roughly about the levels of 5$10 \%$. The maximum reduction ratio of $20 \%$ is achieved for $8 \%$ GF at a speed of 2500 RPM. In recent researches, the usage of nano fuel additives has received significant consideration in the combustion of fuels. The added nano fuel additives act as a catalyst that promotes combustion in a better way (Tamilvanan et al., 2021, Viswanathan and Paulraj, 2020). Investigations on a common rail direct injection system diesel engine fueled with A12O3 nanoparticles blended biodiesel was done (Aalam et al., 2015). The results exhibit a substantial improvement in heat release rate and BTE. The use of copper nanoparticles as additive along with biodiesel could result in an enhancement of $1.13-2.48 \%, 1.42-1.88 \%$, and $5.02-5.79 \%$ for BTE, maximum peak pressure, and maximum heat release rate, respectively (Tamilvanan et al., 2019).

From the previous literature, it is revealed that the diesel engines are suitable for many power train applications, but the only limitation is only higher exhaust NOx emissions. This limitation can be overcome by fumigation with simple modifications in the existing CI engine. Gasoline is found as the most suited fumigation fuel because of its properties like calorific value and volatility, and also, it has better combustion characteristics when compared with remaining fumigation fuels. However, the disadvantages of fumigation are elevated $\mathrm{CO}$ and $\mathrm{HC}$ emissions. On the other hand, a nano fuel additive is also called a combustion inhibitor or catalyst, which promotes the oxidation of $\mathrm{HC}$, resulting in enhanced combustion. Compared to so many nano fuel additives, $\mathrm{Al} 2 \mathrm{O} 3$ received so much attention because of the existence of oxygen molecules that enrich combustion. Based on the inferences obtained from previous literature, the main objective of this investigation is to reduce elevated $\mathrm{CO}$ and $\mathrm{HC}$ emissions of GF along with diesel in a single-cylinder diesel engine. This can be achieved by blending A12O3 nanoadditive liquid with 25 and 50ppm concentrations.

\section{MATERIALS AND METHODS}

\section{Preparation of Nanoadditive Fuels and its Properties}

Adding nanoadditives in base fuel causes progress in the improvement of thermophysical properties (Tamilvanan et al., 2016). Varieties of nanoparticle metal additives were used as fuel additives to diesel/biodiesel. Compared to other metal additives, $\mathrm{Al}_{2} \mathrm{O}_{3}$ showed excellent thermophysical properties such as heat transfer rate and thermal conductivity. In this research work, $\mathrm{Al}_{2} \mathrm{O}_{3}$ nanoliquid was selected because it would blend more easily with 
diesel fuel and also the existence of oxygen in $\mathrm{Al}_{2} \mathrm{O}_{3}$. The required concentration of $\mathrm{Al}_{2} \mathrm{O}_{3}$ is mixed with diesel and placed in an ultrasonicator for proper blending of the liquids. To avoid the phase separation of the liquids, the surfactant SPAN 80 is used here. The properties were tested in the laboratory as per the standard. The fuel properties of gasoline, diesel with 25 ppm of $\mathrm{Al}_{2} \mathrm{O}_{3}$ (25AONP-D), and diesel with $50 \mathrm{ppm}$ of $\mathrm{Al}_{2} \mathrm{O}_{3}(50 \mathrm{AONP}-\mathrm{D})$ are compared with those of diesel and are presented in Table 1.

Table 1. Fuel Properties.

\begin{tabular}{|c|c|c|c|c|}
\hline Particulars & D & Gasoline & 25ANOP-D & 50ANOP-D \\
\hline Density at $15^{\circ} \mathrm{C}\left(\mathrm{kg} / \mathrm{m}^{3}\right)$ & 815 & 737 & 816.5 & 819 \\
\hline Flash point $\left({ }^{\circ} \mathrm{C}\right)$ & 56 & 45 & 51 & 45 \\
\hline Calorific value $(\mathrm{kJ} / \mathrm{kg})$ & 42000 & 43400 & 42100 & 42150 \\
\hline Cetane number & 47 & 5 & 47.5 & 49 \\
\hline
\end{tabular}

\section{Experimental Setup for Gasoline Fumigation with Fuel Map Table}

Generally, the control of fumigation is done by the carburetor or electronic injector with ECU. Four-stroke water-cooled CI engine with single cylinder and 17.5 compression ratio is modified for fumigation, including microcomputer control, modified air intake system with open ECU, and secondary fuel tank with pump. In this research work, PE3, an open ECU from Apex Innovations Inc, is used for controlling fuel injection parameters. Here, the injection duration can be altered in the fuel map table, based on the different input values like throttle position and speed. The representation of the experimental setup is shown in Figure 1. The AVL 444 exhaust gas and AVL 435 smoke meter analyzer are used to measure the smoke and emission values, respectively. The experiment is repeated for different loads of the engine, and open ECU software would control the fumigation rates according to the fuel map table. The GF is done for three different rates of $10 \%, 20 \%$, and $30 \%$ based on energy. The results of the fumigation are optimized, and the optimized fumigation rate is calculated for various loads. Based on the optimal results, $10 \%$ fumigation is best for obtaining better performance and emission (Bharathiraja et al., 2017). The modified fuel map of $10 \%$ fumigation is used for GF for further research. 


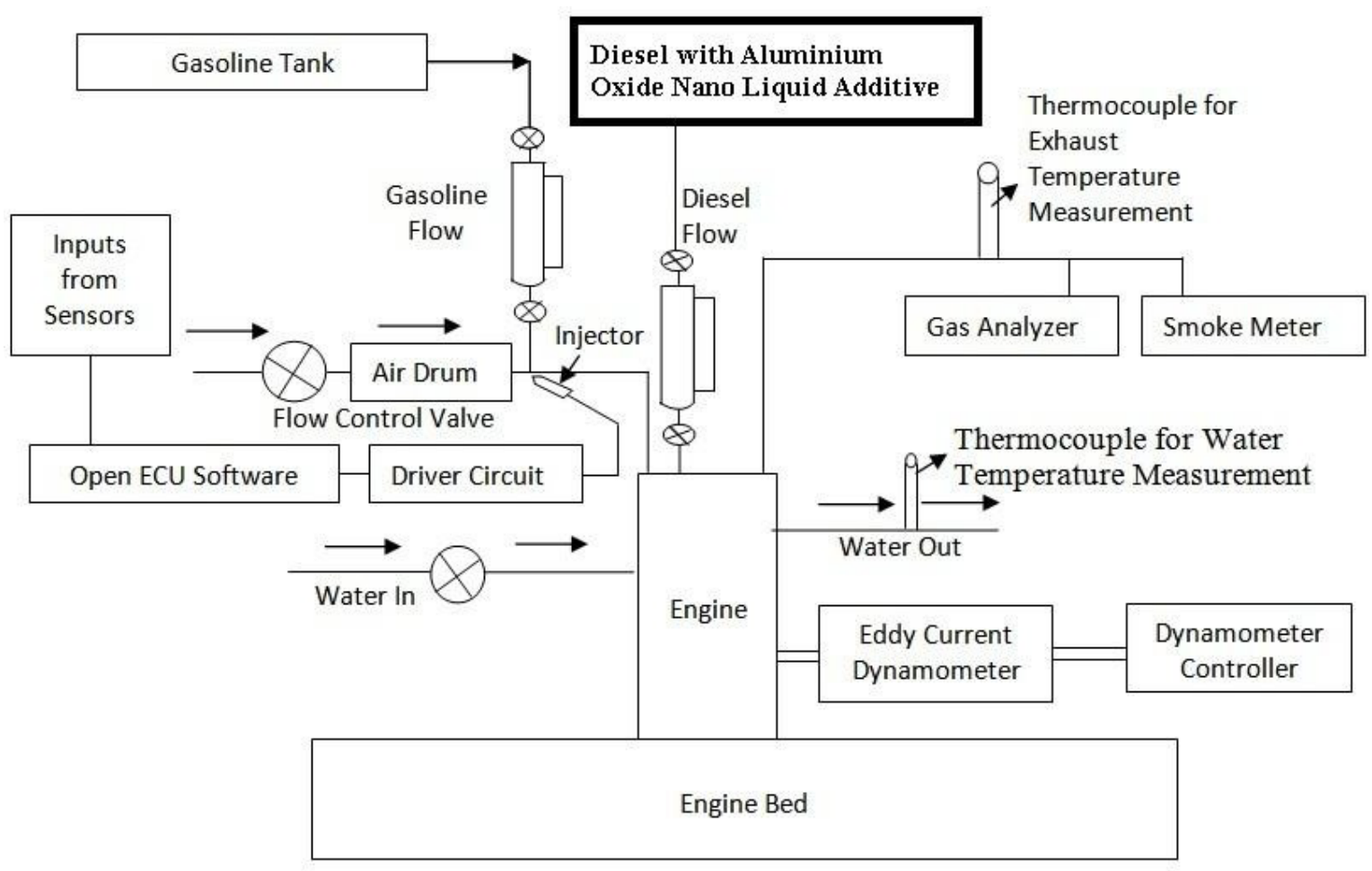

Figure 1. Experimental setup.

\section{RESULTS AND DISCUSSION}

In this present investigation, the experiments were conducted on four modes of operation (mentioned below) under similar operating conditions such five different loads $(0,25,50,75$, and $100 \%)$ and constant speed.

1. Diesel (D) only

2. Diesel with Gasoline Fumigation $(\mathrm{D}+\mathrm{GF})$

3. $25 \mathrm{ppm} \mathrm{Al}_{2} \mathrm{O}_{3}$ nanoadditive blended diesel along with Gasoline Fumigation (25ppmAONP-D+GF)

4. 50ppm $\mathrm{Al}_{2} \mathrm{O}_{3}$ nanoadditive blended diesel along with Gasoline Fumigation (25ppmAONP-D+GF)

\section{Performance Characteristics}

\section{Brake Thermal efficiency}

BTE was decreased about 3.1-4.12\% for GF along with diesel at lower loads, whereas it was increased about $0.86-1.09 \%$ at higher loads when compared to neat diesel mode, which is exposed in Figure 2. The cooling effect of gasoline and leaner air -gasoline mixture (because fumigated gasoline at inlet manifold replaces considerable amount of air entered into the combustion chamber) resulted in longer ignition delay (ID) and poorer combustion, which tends to lower BTE at low loads, whereas at high loads, the higher cylinder temperature and shorter ID make the combustion better, which resulted in higher BTE compared to diesel (Hoseinpour et al., 2018, Viswanathan et al., 2020). Compared to diesel along with GF, there was an improvement of $0.18-5.41 \%$, and $1.60-7.85 \%$ is obtained for GF along with 25 ppm and 50 ppm Al2O3 blended diesel, respectively. Also, an average improvement 
of $1.98 \%$ was obtained for GF along with 50ppm Al2O3 blended diesel when compared to the same with 25ppm additive. This was due to the thermal conductivity and larger surface area to volume ratio of $\mathrm{Al} 2 \mathrm{O} 3$ nanoadditives, which enhanced the fuel droplets evaporation rate and better air-fuel mixing. The above factors ensued in improved combustion for GF with AONP diesel mode when compared to gasoline with neat diesel. Similar improvements in BTE are obtained in previous literature using Al2O3 nanoadditive (El-Seesy et al., 2018, Aalam et al., 2015)

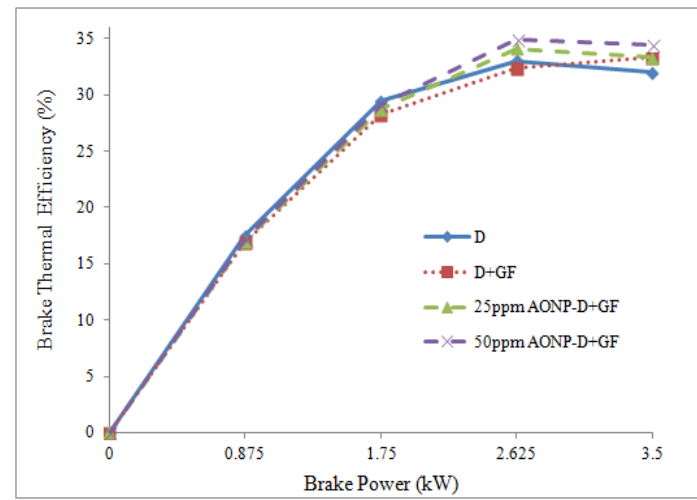

Figure 2. Variations of BTE.

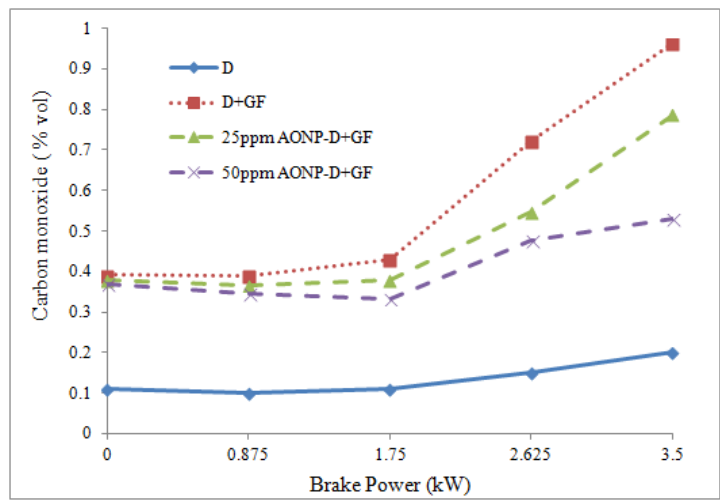

Figure 3. Variations of $\mathrm{CO}$ emission.

\section{Emission Characteristics}

\section{CO Emissions}

$\mathrm{CO}$ emissions are significantly higher for GF operation when compared to neat diesel and also GF with 25 and $50 \mathrm{ppm} \mathrm{Al}_{2} \mathrm{O}_{3}$ nanoadditive diesel blends, which are exposed in Figure 3. The increase in $\mathrm{CO}$ is lesser at low and medium loads, but it is significantly larger at higher loads. The reason for the higher $\mathrm{CO}$ emission of fumigation mode was mainly due to longer ID and cooling effect of gasoline inside the cylinder, which could lead to partial oxidation of the $\mathrm{CO}$ to $\mathrm{CO}_{2}$. And also, the lowered air/fuel ratio related to premixed gasoline would result in elevated $\mathrm{CO}$ emission (Hoseinpour et al., 2018). The $\mathrm{CO}$ emissions GF with 25 and 50ppm $\mathrm{Al}_{2} \mathrm{O}_{3}$ nanoadditive diesel blends were significantly higher than neat diesel and considerably lower than GF along with nanoadditive diesel. The presence of $\mathrm{Al}_{2} \mathrm{O}_{3}$ nanoadditive in diesel along with $\mathrm{GF}$ resulted in an average reduction of $\mathrm{CO}$ emissions about $12.5 \%$ and $23.6 \%$ for $25 \mathrm{ppm}$ and $50 \mathrm{ppm}$, respectively, when compared to fuel without additive. The reasons for the reduction of $\mathrm{CO}$ emissions of GF with $\mathrm{Al}_{2} \mathrm{O}_{3}$ nanoadditive were mainly due to catalytic activity of nano fuel additive and existence of oxygen molecule in nanofuel additive, which took part in the oxidation of $\mathrm{CO}$ to $\mathrm{CO}_{2}$, resulting in enhanced combustion. Moreover, the $\mathrm{CO}$ emissions were further reduced to 3-32\% when the concentration of $\mathrm{Al}_{2} \mathrm{O}_{3}$ nanoadditive was increased from $25 \mathrm{ppm}$ to $50 \mathrm{ppm}$. Thus, it has been proved the catalytic action of nanofuel additive, which took part in the combustion of fuel. 


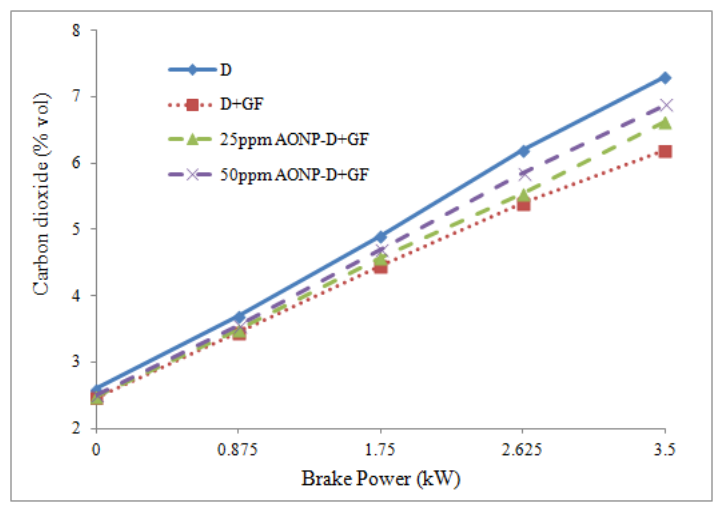

Figure 4. Variations of $\mathrm{CO}_{2}$ emission.

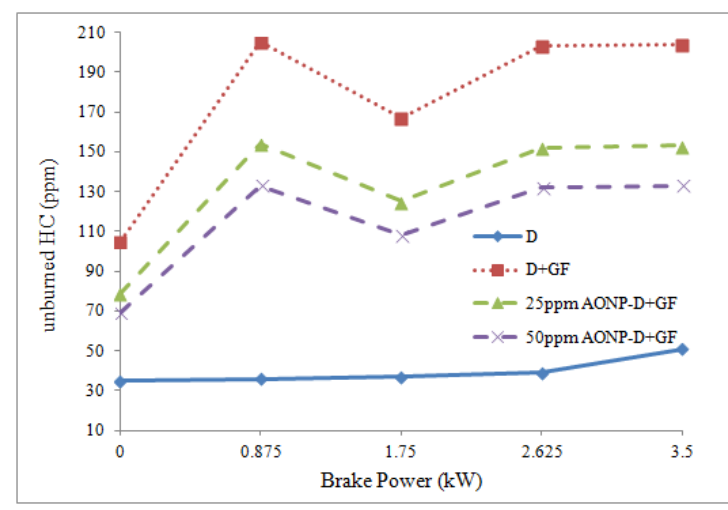

Figure 5. Variations of UBHC emission.

\section{$\mathrm{CO}_{2}$ Emissions}

$\mathrm{CO}_{2}$ emission is decreased by about $3.65-5.76 \%$ for GF with diesel when compared with neat diesel at overall working conditions. At every load, $\mathrm{CO}_{2}$ emission was reduced to some extent for GF when compared to diesel, which is depicted in Figure 4. The existence of gasoline in a premixed air-fuel mixture in an intake manifold offers a smaller quantity of oxygen into a combustion chamber, which resulted in incomplete combustion and thus diminishes $\mathrm{CO}_{2}$ formation. The cooling effect of gasoline reduces in-cylinder combustion temperature that leads to incomplete combustion, and it resulted in lower $\mathrm{CO}_{2}$ emission (Hoseinpour et al., 2018). The addition of $\mathrm{Al}_{2} \mathrm{O}_{3}$ nanoadditives to diesel along with GF could further increase $\mathrm{CO}_{2}$ emissions. The result also showed that an increase of $\mathrm{CO}_{2}$ emissions about $0.40-6.95 \%$ and $1.21-11.1 \%$ is obtained for GF along with $25 \mathrm{ppm}$ and $50 \mathrm{ppm}$ $\mathrm{Al}_{2} \mathrm{O}_{3}$ nanoadditives, respectively, when compared to the same without additive. It was noticed that $\mathrm{Al}_{2} \mathrm{O}_{3}$ nanoadditives had a significant constructive effect on $\mathrm{CO}_{2}$ emissions, which was probably attributable to the presence of oxygen molecule in $\mathrm{Al}_{2} \mathrm{O}_{3}$ nanoadditive, better air-fuel mixing of premixed gasoline, shorter ID, and superior catalytic activity, and the higher surface-to-volume ratio resulted in enhanced combustion. These above factors promoted the effective conversion of $\mathrm{CO}$ to $\mathrm{CO}_{2}$ and thus resulted in higher $\mathrm{CO}_{2}$ emission for nanoadditives blended fuels (El-Seesy et al., 2018).

\section{Unburned HC Emissions}

GF operation showed higher $\mathrm{HC}$ emissions when compared to neat diesel operation, which is depicted in Figure 5. During GF mode operation, the air/gasoline mixture absorbed in crevices and cylinder wall and rich airgasoline fuel mixture might be the reason for the formation of unburned HC. Additionally, at low engine loads, there was a possibility of inferior combustion due to lean air/fuel mixture, longer ID, and its cooling effect, resulting in higher unburned $\mathrm{HC}$ emissions (Bharathiraja et al., 2017). The addition of nano $\mathrm{Al}_{2} \mathrm{O}_{3}$ additive with diesel and GF led to a reduction in the $\mathrm{HC}$ emission as compared to GF without additive. The result showed that an average reduction of unburned $\mathrm{HC}$ emissions of about $25.04 \%$ and $35.04 \%$ was obtained for $25 \mathrm{ppm}$ and $50 \mathrm{ppm}$ of $\mathrm{Al}_{2} \mathrm{O}_{3}$ nanoadditive blended diesel along with $\mathrm{GF}$, respectively, when compared to GF without $\mathrm{Al}_{2} \mathrm{O}_{3}$ nanoadditive. And the same was again reduced to an average of $13.37 \%$ when the concentration of $\mathrm{Al}_{2} \mathrm{O}_{3}$ nanoadditive was increased from $25 \mathrm{ppn}$ to $50 \mathrm{ppm}$. These results revealed positive effects on the enhanced combustion process, which led to the reduction of unburned $\mathrm{HC}$ emissions as a result of the existence of oxygen molecules in $\mathrm{Al}_{2} \mathrm{O}_{3}$ nanoadditives (El-Seesy et al., 2018). 


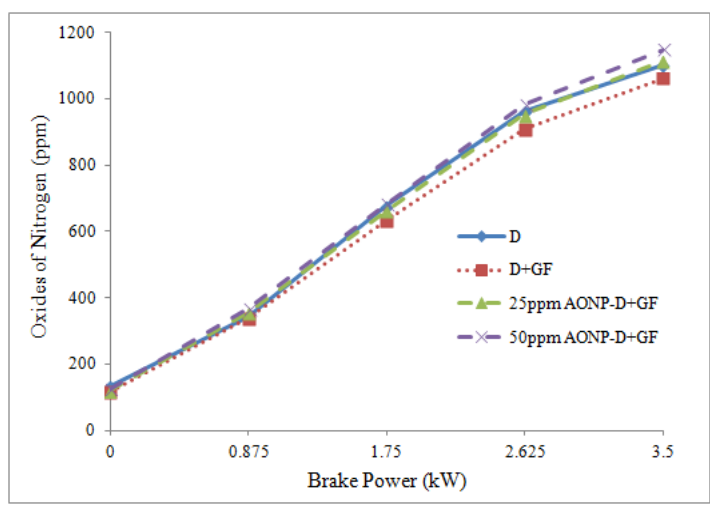

Figure 6. Variations of NOx emission.

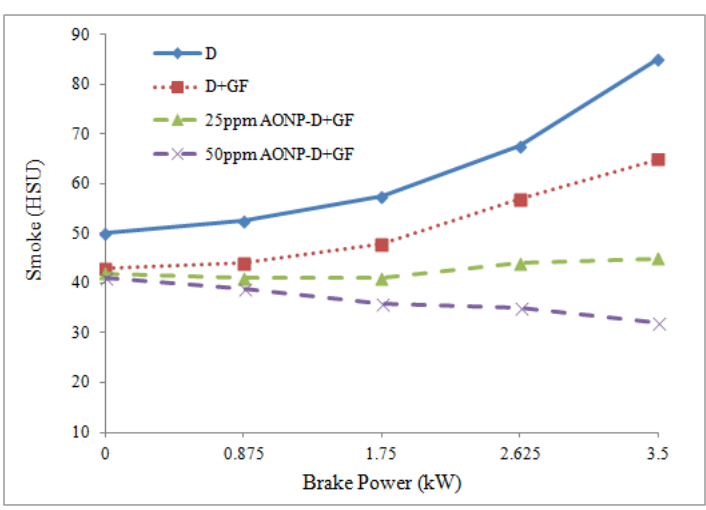

Figure 7. Variations of Smoke Opacity.

\section{NO Emissions}

NOx emissions decrease about $1.1-14.6 \%$ for GF with diesel when compared to diesel at all loads as exposed in Figure 6. This is owing to the higher specific heat of the gasoline-air mixture than that of the air inside the combustion chamber, where the gasoline consumed a larger amount of heat energy and thus resulted in longer ID and reduced in-cylinder temperature (Ou et al., 2012, Hoseinpour et al., 2018). The addition of nano Al2O3 additive with diesel and GF led to an increase of NOx emission as compared to neat diesel and GF without Al2O3 nanoadditive diesel. An increase of NOx emissions of about $1.18-3.49 \%$ and $0.84-6.72 \%$ for GF along with $25 \mathrm{ppm}$ and 50ppm Al2O3 nanoadditive diesel, respectively, when compared to neat diesel is also observed. The existence of oxygen molecule in A12O3 nanoadditive blended fuel would provide sufficient oxygen during the combustion process, which may raise the maximum in-cylinder temperature that would affect additional NOx formation. There was a small difference of about 3.05\% exist in NOx emissions concerning the dose level of nanoparticles from $25 \mathrm{ppm}$ to $50 \mathrm{ppm}$ in the diesel fuel along with GF. This consequence might be due to superior combustion fuel blends as a result of further shorter ID with 50ppm nanoadditive (El-Seesy et al., 2018).

\section{Smoke Opacity}

The smoke opacity decreases about $12.1-23.4 \%$ for GF with diesel when compared to neat diesel at overall operating conditions, which is exposed in Figure 7. The addition of 25ppm and 50ppm $\mathrm{Al}_{2} \mathrm{O}_{3}$ nanoadditive to diesel along with GF could result in further reduction of smoke opacity about $15.4-46.4 \%$ and $17.6-61.7 \%$, respectively, when compared to neat diesel. It is also noticed that a reduction of smoke opacity about $2.3-30.7 \%$ and $4.6-50.7 \%$ was obtained for $25 \mathrm{ppm}$ and $50 \mathrm{ppm}$ of $\mathrm{Al}_{2} \mathrm{O}_{3}$ nanoadditive blended diesel along with GF respectively when compared to GF without $\mathrm{Al}_{2} \mathrm{O}_{3}$ nanoadditive. The increase in the concentration of $\mathrm{Al}_{2} \mathrm{O}_{3}$ from $25 \mathrm{ppm}$ to 50ppm resulted in further reduction of smoke opacity about $2-28 \%$ over the entire operating region. At low load, there was no substantial reduction in the smoke opacity for $\mathrm{Al}_{2} \mathrm{O}_{3}$ blended fuels. However, at medium to high loads, there were considerable large reductions above $30 \%$. GF lowered the relative fuel-air ratio inside the combustion chamber of the cylinder, which decreases the amount of diesel contribution to the diffusion combustion phase that resulted in the reduction of soot formation (Karthickeyan et al., 2019). Also, the existence of $\mathrm{Al}_{2} \mathrm{O}_{3}$ in diesel fuels could act as a catalyst that promotes better combustion. 


\section{Combustion Characteristics}

\section{In-cylinder Pressure with Crank Angle}

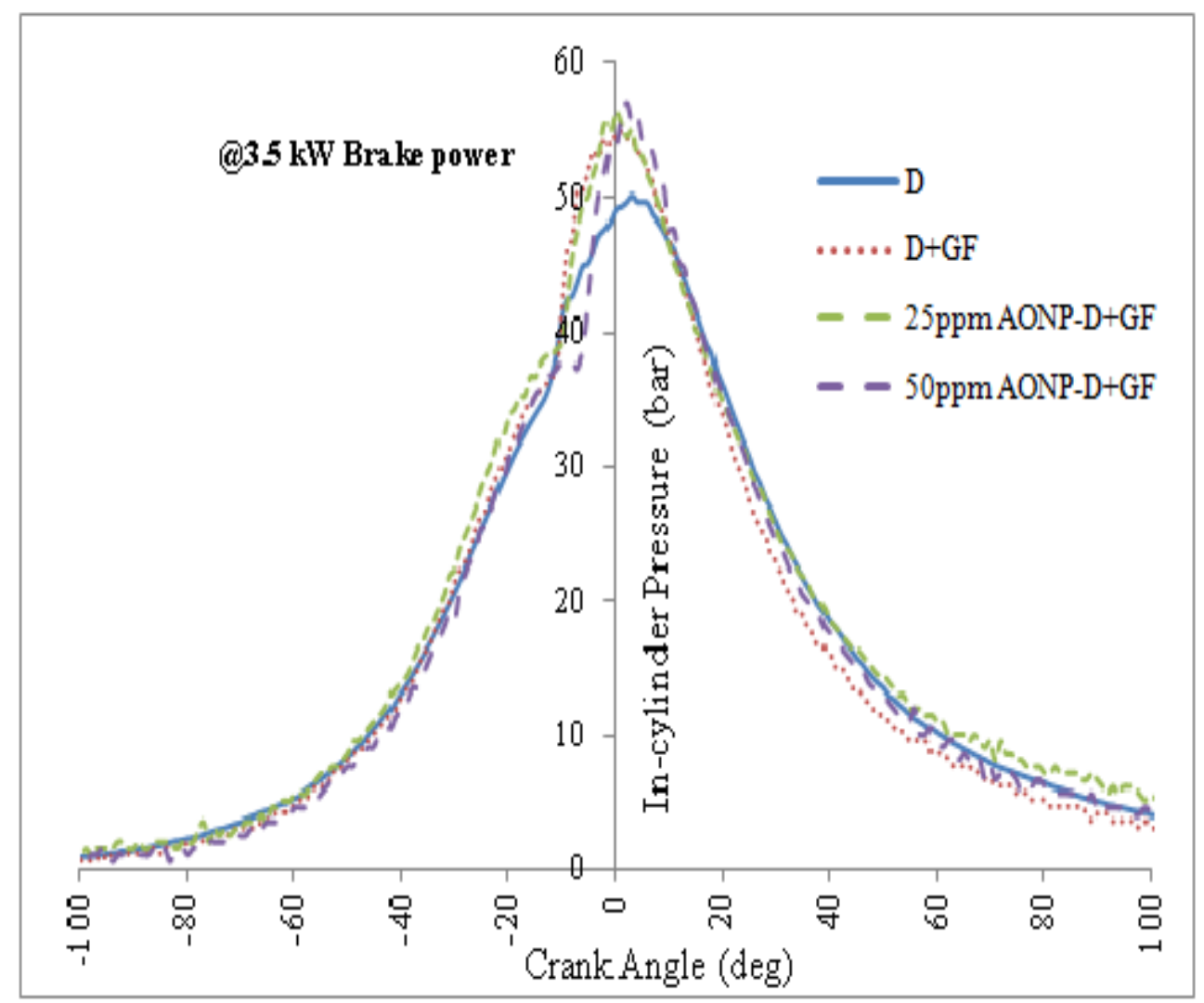

Figure 8. Variations of In-cylinder Pressure with Crank Angle for different fuel blends.

The GF with diesel has a $9.86 \%$ higher peak pressure value than neat diesel, which is exposed in Figure 8 . The fumigation of the gasoline could increase the quantity of the premixed fuel inside the combustion chamber (Ou et al., 2012). This resulted in an increased ID period, which provides more time to make a homogeneous mixture before start of combustion (Wang et al., 2020). Consequently, this led to a higher pre-mixed combustion phase and a shorter diffusion phase of combustion (Jamrozik et al., 2018). The GF along with 25ppm and 50ppm $\mathrm{Al}_{2} \mathrm{O}_{3}$ nanoadditive diesel has $12.78 \%$ and $13.98 \%$, respectively, higher peak pressure value when compared to that of neat diesel. Also, the GF along with 25ppm and 50ppm $\mathrm{Al}_{2} \mathrm{O}_{3}$ nanoadditive diesel has $2.12 \%$ and $3.77 \%$, respectively, higher peak pressure value than $\mathrm{GF}$ without $\mathrm{Al}_{2} \mathrm{O}_{3}$ nanoadditive diesel. Conversely, the addition of $\mathrm{Al}_{2} \mathrm{O}_{3}$ nanoadditive to diesel along with GF reduced the ignition delay period to minimum extent when compared to neat diesel with fumigation. The concentration of nano fuel additive is increased from $25 \mathrm{ppm}$ to $50 \mathrm{ppm}$ and resulted in a slight improvement about $1.07 \%$ higher pressure. This was owing to the more catalytic action of $\mathrm{Al}_{2} \mathrm{O}_{3}$ nanoadditive (Aalam et al., 2015). 


\section{Cumulative Heat Release Rate}

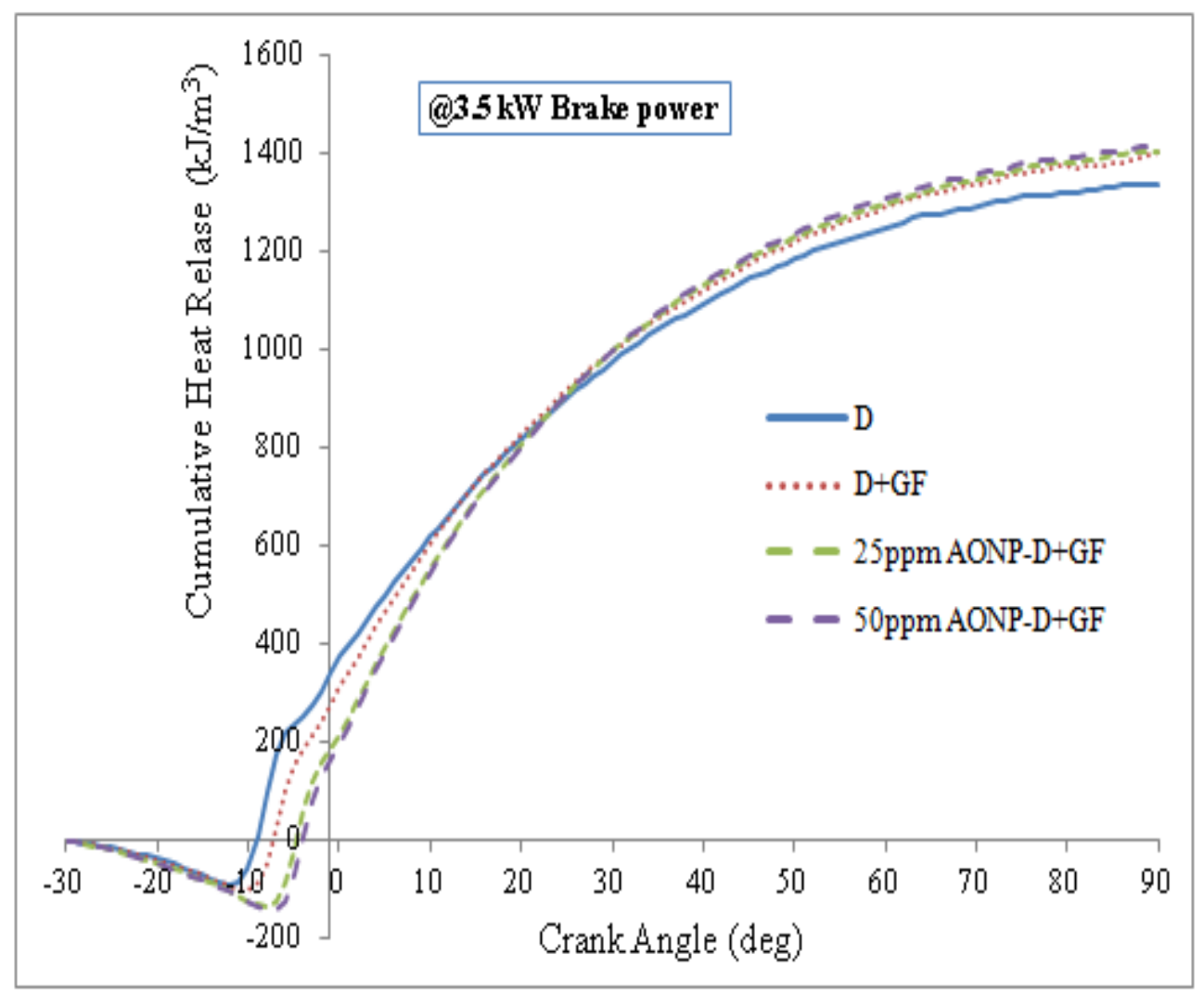

Figure 9. Variations of Cumulative heat release with Crank Angle for different fuel blends.

Figure 9 shows that the maximum cumulative heat release rate (CHRR) of GF with diesel was $4.54 \%$ higher than neat diesel. It is observed that the maximum CHRR of 25 and 50ppm of $\mathrm{Al}_{2} \mathrm{O}_{3}$ nanoadditive to diesel along with GF is $5.04 \%$ and $5.79 \%$ higher than neat diesel, respectively. Also, it is noticed that maximum CHRR of 25 and 50ppm of $\mathrm{Al}_{2} \mathrm{O}_{3}$ nanoadditive to diesel along with GF was $0.21 \%$ and $0.92 \%$, respectively, higher than GF along with nanoadditive diesel. The concentration of nanofuel additive was increased from $25 \mathrm{ppm}$ to $50 \mathrm{ppm}$ and resulted in a slight enhancement of maximum CHRR, which is about $0.71 \%$. The CHRR rate for GF with $\mathrm{Al}_{2} \mathrm{O}_{3}$ nanoadditive is lower before TDC as compared to those of neat diesel and diesel with GF. This is mainly due to the higher thermal conductivity of $\mathrm{Al}_{2} \mathrm{O}_{3}$ nanoadditive, which absorbs a larger amount of heat from the combustion chamber (El-Seesy et al., 2018). The concentration was increased from $25 \mathrm{ppm}$ to $50 \mathrm{ppm}$ and resulted in a slightly higher cumulative heat release rate, which was happened due to the presence of additional oxygen and superior catalytic activity of nanoadditive in fuel blends (Karthickeyan, 2019).

\section{CONCLUSION}

The following conclusions are obtained from the results of testing the GF in open ECU with $\mathrm{Al}_{2} \mathrm{O}_{3}$ nanoliquid blended diesel in DI diesel engine. GF up to $10 \%$ with $\mathrm{Al}_{2} \mathrm{O}_{3}$ nanoliquid blended diesel has significantly higher BTE about $0.86-1.09 \%$ and $0.18-5.41 \%$ compared to diesel mode and diesel with GF mode, respectively. The 
AONP diesel fuel with GF could show lower $\mathrm{CO}$ and unburned $\mathrm{HC}$ emissions throughout engine loading conditions when compared to a diesel with GF mode. This was due to improved combustion of $\mathrm{Al}_{2} \mathrm{O}_{3}$ nanoliquid blended fuel.

The smoke opacity of AONP diesel with GF was considerably reduced when compared to neat diesel and diesel with GF at medium to high loads, while AONP diesel with GF has elevated $\mathrm{NO}_{\mathrm{x}}$ emission compared to all other modes except GF with neat diesel. $\mathrm{CO}, \mathrm{HC}$, and $\mathrm{NO}_{\mathrm{x}}$ emissions of AONP diesel fuel with GF mode were decreased considerably, and BTE was slightly increased as the dosage level was increased from $25 \mathrm{ppm}$ to $50 \mathrm{ppm}$. It is evident that the drawbacks of using $\mathrm{GF}$ in conventional $\mathrm{CI}$ engine were eliminated by adding $\mathrm{Al}_{2} \mathrm{O}_{3}$ nanoliquid additive to diesel fuel.

\section{ACKNOWLEDGMENT}

The authors would like to thank the Management and Administration of Kongu Engineering College for providing the "Seed Grant Research Scheme- KEC/R\&D/SGRS/01/2020".

\section{REFERENCES}

Aalam, C. S., Saravanan, C. \& Kannan, M. 2015. Experimental investigations on a CRDI system assisted diesel engine fuelled with aluminium oxide nanoparticles blended biodiesel. Alexandria Engineering Journal, 54: 351-358.

Ayyasamy, T., Balamurugan, K. \& Duraisamy, S. 2018. Production, performance and emission analysis of Tamanu oil-diesel blends along with biogas in a diesel engine in dual cycle mode. International Journal of Energy Technology and Policy, 14: 4-19.

Bharathiraja, M., Venkatachalam, R., Murugesan, A. \& Tiruvenkadam, N. 2017. Experimental investigation of a novel alcohol fumigation in a single-cylinder constant speed diesel engine. International Journal of Ambient Energy, 38: 794-802.

Bharathiraja, M., Venkatachalam, R. \& Senthilmurugan, V. 2019. Performance, emission, energy and exergy analyses of gasoline fumigated DI diesel engine. Journal of Thermal Analysis and Calorimetry, 136: 281-293.

El-Seesy, A. I., Attia, A. M. \& El-Batsh, H. M. 2018. The effect of Aluminum oxide nanoparticles addition with Jojoba methyl ester-diesel fuel blend on a diesel engine performance, combustion and emission characteristics. Fuel, 224: 147-166.

Hoseinpour, M., Sadrnia, H., Tabasizadeh, M. \& Ghobadian, B. 2017. Energy and exergy analyses of a diesel engine fueled with diesel, biodiesel-diesel blend and gasoline fumigation. Energy, 141: 2408-2420.

Hoseinpour, M., Sadrnia, H., Tabasizadeh, M. \& Ghobadian, B. 2018. Evaluation of the effect of gasoline fumigation on performance and emission characteristics of a diesel engine fueled with B20 using an experimental investigation and TOPSIS method. Fuel, 223: 277-285.

Jamrozik, A., Tutak, W., Gruca, M. \& Pyrc, M. 2018. Performance, emission and combustion characteristics of CI dual fuel engine powered by diesel/ethanol and diesel/gasoline fuels. Journal of Mechanical Science and Technology, 32: 2947-2957.

Karthickeyan, V. 2019. Effect of combustion chamber bowl geometry modification on engine performance, combustion and emission characteristics of biodiesel fuelled diesel engine with its energy and exergy analysis. Energy, 176: 830-852. 
Karthickeyan, V., Ashok, B., Nanthagopal, K., Thiyagarajan, S. \& Geo, V. E. 2019. Investigation of novel Pistacia khinjuk biodiesel in DI diesel engine with post combustion capture system. Applied Thermal Engineering, 159: 113969.

Ou, L. J., Wang, C. M., Qian, Y. J., Huang, W., Zhu, S. W. \& Sun, J. 2012. Effect of gasoline fumigation on diesel engine performance and emissions. Applied Mechanics and Materials, Trans Tech Publ: 1744-1748.

Şahin, Z. \& Durgun, O. 2013. Improving of diesel combustion-pollution-fuel economy and performance by gasoline fumigation. Energy conversion and management, 76: 620-633.

Sahin, Z., Durgun, O. \& Bayram, C. 2012. Experimental investigation of gasoline fumigation in a turbocharged IDI diesel engine. Fuel, 95: 113-121.

Sekar, D., Venkadesan, G. \& Viswanathan, K. 2021. Experimental evaluation of orange oil biodiesel in compression ignition engine with various bowl geometries. Energy Sources, Part A: Recovery, Utilization, Environmental Effects: 1-12.

Tamilvanan, A., Balamurugan, K., Mohanraj, T., Selvakumar, P. \& Madhankumar, B. 2021. Parameter optimization of copper nanoparticle synthesis by electrodeposition process using RSM and CS. Materials Today: Proceedings, 45: 751-756.

Tamilvanan, A., Balamurugan, K., Ponappa, K. \& Madhan Kumar, B. 2016. Using response surface methodology in synthesis of ultrafine copper nanoparticles by electrolysis. International Journal of Nanoscience, 15: 1650001.

Tamilvanan, A., Balamurugan, K. \& Vijayakumar, M. 2019. Effects of nano-copper additive on performance, combustion and emission characteristics of Calophyllum inophyllum biodiesel in CI engine. Journal of Thermal Analysis and Calorimetry, 136: 317-330.

Viswanathan, K. \& Paulraj, A. 2020. A comprehensive study on the performance and emission characteristics of a diesel engine with the blends of diesel, jojoba oil biodiesel, and butylated hydroxyl anisole as an alternative fuel. Energy Sources, Part A: Recovery, Utilization, Environmental Effects: 1-15.

Viswanathan, K., Wang, S. \& Esakkimuthu, S. 2020. Impact of yttria stabilized zirconia coating on diesel engine performance and emission characteristics fuelled by lemon grass oil biofuel. Journal of Thermal Analysis Calorimetry: 1-13.

Wang, S., Karthickeyan, V., Sivakumar, E. \& Lakshmikandan, M. 2020. Experimental investigation on pumpkin seed oil methyl ester blend in diesel engine with various injection pressure, injection timing and compression ratio. Fuel, 264: 116868.

Wang, S., Viswanathan, K., Esakkimuthu, S. \& Azad, K. 2021. Experimental investigation of high alcohol low viscous renewable fuel in DI diesel engine. Environmental Science Pollution Research, 28: 12026-12040. 